\title{
Redes sociais em jogos online: a dinâmica da interação social no World of Warcraft
}

\section{Telma Johnson, Antônio Augusto Braighi, Roberta Almeida, Ana Amélia Hamdan e Diego Miranda}

\section{Resumo}

Este artigo aborda a dinâmica das interações sociais entre os players do jogo online World of Warcraft (WoW). 0 percurso teórico-metodológico seguiu uma orientação relacional focada em três dimensões - estrutura, conteúdo e função - para a apreensão dos processos e práticas comunicativas no ambiente WoW. 0 trabalho, de natureza qualitativa, valoriza a leitura dos próprios jogadores sobre os fatores que explicam o estabelecimento e a manutenção de uma rede social, que extrapola os limites do jogo, amplia-se em outras modalidades de socialização virtual e firma-se no contato físico.

\section{Palavras-chave}

Interação. Jogos. Comunicação Mediada por Computador (CMC).

Telma Johnson I tjohnson@globo.com

Doutora em Comunicação e Sociabilidade Contemporânea pela Universidade Federal de Minas Gerais - UFMG. Pesquisadora associada do Grupo de Pesquisa Imagem e Sociabilidade (GRIS) da Universidade Federal de Minas Gerais - UFMG.

Antônio Augusto Braighi I antonioaugustorp@yahoo.com.br Especialista em Comunicação e Imagens Midiáticas pela UFMG.

Roberta Almeida | robsalmeida@yahoo.com.br Especialista em Comunicação e Imagens Midiáticas pela UFMG.

Ana Amélia Hamdan I anaameliahamdan@yahoo.com.br Especialista em Comunicação e Imagens Midiáticas pela UFMG.

Diego Miranda I dimiranda@pop. com.br Especialista em Comunicação e Imagens Midiáticas pela UFMG.

\section{Introdução}

0 mundo vem assistindo a um aumento gradativo do acesso à Internet via banda larga e à progressiva inclusão digital que têm sido, entre outros fatores, a base para a projeção de um crescimento exponencial de usuários na grande rede. Paralelamente, corre 0 desenvolvimento dos jogos virtuais - a adaptação dos videogames para o computador e o investimento maciço neste mercado por grandes empresas multinacionais. A combinação desses dois fatores atrai um número cada vez maior de indivíduos que se utilizam da web para interagir com pessoas de todo o mundo através dos games massivos online.

Esse fenômeno é observado no World of Warcraft (WoW), entretenimento do segmento Massive Multiplayer Online Role Playing Games (MMORPG), traduzido livremente como Jogos Massivos Online de Multiusuários Avatares. 0 jogo vem atraindo cada vez mais a atenção devido ao forte apelo que exerce junto ao público. Em dezembro de 2008, já eram 11,5 milhões de jogadores cadastrados em vários países ${ }^{1}$. No campo da pesquisa em Comunicação Mediada 
por Computador (CMC), questionamos sobre a existência de uma rede social nesse ambiente, quais seriam as suas especificidades, quais seriam as formas, graus e extensões de interação social e os fatores que explicam o surgimento e a sustentação desse fenômeno social online.

Para responder a essas questões, este artigo inicialmente faz um resgate teórico sobre a noção de redes sociais, entendidas aqui como redes de comunicação; em seguida, relata os achados da observação empírica do WoW, dentro de suas dimensões estrutural, de conteúdo e de função; descreve como esses passos iniciais permitiram a operacionalização dos conceitos-chave que auxiliaram na construção de um questionário online com perguntas abertas aos jogadores; e, por fim, analisa e interpreta os dados revelados quanto ao estabelecimento e os processos de interações sociais no jogo.

\section{0 estado da arte no estudo das redes sociais}

A noção de rede não é recente e se aplica a vários campos (redes de transmissão de doenças, redes ecológicas, redes metabólicas, redes de transmissão elétrica, entre outras). França (2002, p. 59) observa que, num sentido literal, o termo rede se refere a um entrelaçamento de linhas, a um conjunto de nós interconectados, remetendo "à forma, à morfologia de um sistema. Comunicação

em rede, sociedade em rede são expressões para significar a interconexão de elementos, processos, sentidos que marcam as relações comunicativas e a construção da vida social".

Na comunicação e nas relações sociais, França (2002) enfatiza que a noção de rede se reconfigurou com o surgimento dos novos suportes telemáticos, mas a novidade está "[...] no desenho e extensão das redes, na diversidade dos cruzamentos, na quantidade/ qualidades dos elementos conectados ou desconectados, na sua dinâmica espaçotemporal" (FRANÇA, 2002, p. 59).

Mas é sobretudo 0 advento de profundas modificações no domínio da realidade - a "revolução" das tecnologias de informação, o desenvolvimento das redes digitais, a globalização - que vem de fato derrubar a concepção linear da comunicação. Desenvolvem-se tecnologias interativas (cresce a internet, o universo online altera a prática e os usos dos meios tradicionais, assistimos a um sistema de informação operando em rede, etc.) - e a interatividade entra na ordem do dia (FRANÇA, 2002, p. 63).

Os estudos das redes sociais mediadas por computador têm-se, invariavelmente, centrado na estrutura das redes e na utilização da técnica de Análise de Redes Sociais (ARS), cuja perspectiva segue a abordagem quantitativa, estática e descritiva das relações existentes dentro das redes. 0 estudo de base estrutural privilegia 0 aspecto 
arquitetural dos laços da rede, enfatizando o seu tamanho, os graus de conexão (densidade) e os tipos de relacionamento como fortes ou fracos.

Esses estudos (BLAU, 1974; BURT, 1980;

COLEMAN, 1990) partem do pressuposto de que a estrutura de uma rede tem um impacto mais profundo sobre o comportamento dos atores do que as normas, valores ou outros estados subjetivos. A centralidade em variáveis e atributos (faixa etária, sexo, raça etc.), contudo, negligencia a interação social e perde de vista a orientação relacional, a dinâmica dos processos comunicativos. Ao reduzir as redes sociais à perspectiva estrutural, esses estudos deixam de observar as instituições de uma sociedade ou grupo social - tanto materiais como sistemas de ideias, de valores, de significações - dentro de seus aspectos duradouros e, ao mesmo tempo, como auto-instituintes, auto-mutáveis e em constante devir.

Na contramão da tendência das pesquisas sobre redes sociais, este estudo prioriza a dinâmica da rede social formada no jogo online WoW, partindo do pressuposto de que ela não pode ser compreendida sem se levar em consideração como as relações são criadas, mantidas, dissolvidas, recriadas. Embora não haja uma única "teoria da rede", um princípio básico da perspectiva de redes sociais que adotamos neste trabalho é que elas se fundamentam em uma unidade de base que é a relação entre os agentes sociais. As redes sociais em geral apresentam três características distintas - estrutura, conteúdo e função. Além da estrutura, como apresentamos acima, o conteúdo de uma rede diz respeito aos tipos de recursos materiais e imateriais em fluxo, ou seja, as atitudes, opiniões, memória coletiva, experiência etc. dos sujeitos envolvidos.

Como as redes operam de forma diferente em diferentes grupos, as suas funções também variam (PEARLIN; ANESHENSEL, 1986). Quando falamos a respeito da função de uma rede, estamos nos referindo ao propósito da rede, e as respostas chamam para perguntas tais como: é uma rede de entretenimento, econômica, cultural, pedagógica?, é voluntária?, é pública, secreta ou clandestina?, quem pode entrar e em que condições?, qual o seu grau de autonomia e democracia?, qual o grau de autoreferencialidade (está voltada para si mesmo ou para 0 exterior)?, há um compromisso social?

Atualmente, assistimos à emergência de uma série de redes sociais online, colocando indivíduos em conexão através de interações telemáticas distintas e em áreas de interesses específicos. Em busca de uma contextualização situacional e pragmática, interessamo-nos por compreender essas redes a partir de um olhar epistemológico relacional, que se contrapõe ao modelo transmissivo-informacional de muitos para muitos, que por muito tempo dominou os estudos dos meios de comunicação de massa tradicionais. A perspectiva pragmática nos leva à percepção de que os indivíduos são socialmente 
constituídos e que o contexto social dentro do qual isso ocorre é sempre um complexo de práticas situadas.

Colina et al. (2002) observam que a orientação relacional guarda uma maior equivalência com que é o processo de constituição do social. Os autores argumentam que o social não se constrói através de categorias ou atributos senão de laços ou de vínculos entre sujeitos. As ações são pertinentes e consideradas na medida em que expressam propriedades emergentes de conexão ou ligação entre as unidades de observação. Além disso, uma relação está vinculada a outras relações que constituem seu contexto e tanto a relação como o contexto relacional se modificam nos processos sociais e, portanto, não podem ser estudados do ponto de vista estático.

\section{World of WarCraft como objeto de estudo}

Entre tantos games para computador disponíveis no mercado, 0 WoW se destaca pelo número global de jogadores, muitos residentes no $\mathrm{Brasil}^{2}$, apesar de ser um jogo que exige conexão banda larga e o pagamento de uma mensalidade fixa de US\$ 15 mensais. A origem vem do tradicional RPG, criado nos Estados Unidos na década de 1970 e amplamente divulgado no Brasil em meados de
1990. Com o surgimento e a popularização dos computadores pessoais, principalmente com 0 advento da Internet comercial, o filão de jogos RPG apresentava-se como um ótimo nicho para os desenvolvedores de jogos eletrônicos. Entre os MMORPGs com gráficos visuais, o precursor foi 0 jogo Neverwinter Nights, de 1991, abrindo espaço para o nascimento de muitos outros games do gênero, voltados para os PCs.

Entre eles estava 0 WoW, que teve sua primeira edição lançada em 1994. Na época, o título era WarCraft: Orcs and Humans. Com o sucesso das primeiras versões e o desenvolvimento dos gráficos 3D vinculados ao estabelecimento de 'aventuras' muito mais complexas, foi criado o 'mundo' de Warcraft. Nas versões atuais, o jogador controla um personagem, em um planeta 'mágico', que deve cumprir determinadas missões. Nessa terra paralela, existe uma divergência entre duas facções ${ }^{3}$ e cada personagem deve cumprir tarefas para 0 bem e a segurança de sua cidade/grupo/facção. Em cada lado existem raças (humanos, elfos, anões, entre outros), classes (como guerreiros, magos e sacerdotes) e profissões, das mais variadas, que servem como aporte para que o jogador e seu personagem possam adquirir 'bens' no jogo.

Esses elementos, por si só, demonstram a necessidade da cooperação e do estabelecimento

Não há uma estatística oficial do número de jogadores do WoW no Brasil. Isso se deve ao fato de que todos os servidores do jogo estão localizados nos Estados Unidos e não há versão em língua portuguesa. Contudo, pelo número de comunidades em redes sociais, blogs e fóruns de discussão na Internet, calcula-se uma grande representatividade do jogo no Brasil. Só no Orkut há uma variedade de comunidades do WoW no Brasil, a maior delas com 66 mil membros.

Conceito comungado entre os jogadores, que poderia ser melhor compreendido como 'nações' em guerra. 
de parcerias para alcançar determinados objetivos no jogo. Assim, começam a se formar grupos, seja para as conquistas, seja para a defesa, que podem chegar ao estágio de guildas - gangues maiores nas quais a interação social se estabelece de forma mais ampla. 0s grupos são formados para disputas e aventuras como as raids, as battlegrounds e as arenas, em que, desde que saiam vitoriosos, os integrantes recebem recompensas e sobem os níveis de potência no jogo.

As formas de participação nesses grupos são bem variadas. Existem conjuntos simples, de até cinco pessoas, formados por meio de convites, tradicionalmente formados mais no início do jogo. No caso das guildas, a entrada é moderada e depende da ideologia da 'administração', mantida pelos próprios jogadores. Alguns optam por formar grupos pequenos, apenas com pessoas de maior afinidade, ou com bons players - com maior nível no game. Outras são pretensas em quantidade e montam estruturas com grande número de membros.

Com base nas guildas, é possível entender 0 estabelecimento das redes sociais, sobretudo se levarmos em conta a sua dimensão estrutural. Nesse aspecto, ao estudar o WoW, Rodrigues e Mustaro (2008) talvez sejam as precursoras. Advindas das ciências exatas, as pesquisadoras discutiram a formação e os "cruzamentos" dessas redes através de tabulação em softwares. 0 estudo com 21 guildas as levou a identificar a existência de redes sociais no game, concluindo que:

A análise das redes sociais resultantes da coleta de dados das guildas permitiu verificar que existe uma relação inversamente proporcional entre 0 tamanho da guilda e sua densidade, ou seja, quanto menor a guilda mais densidade ela apresenta. Isso pode ser explicado pelo estabelecimento de uma relação mais próxima entre os membros que ao se conhecerem melhor, ao jogar juntos, apresentam performance mais elevada. (RODRIGUES; MUSTARO, 2008, p. 39).

Para exemplificar esse fragmento da análise das pesquisadoras, apresentamos abaixo a representação gráfica de duas guildas distintas. A Figura 01 apresenta 109 pontos (jogadores) e 941 relações entre eles (baseadas, superficialmente, na relação estabelecida entre players em uma determinada ação/aventura), enquanto que a Figura 02 representa, respectivamente, 106 membros e 1.183 relações (RODRIGUES; MUSTAR0, 2008). Contudo, para as nossas indagações, não basta saber onde estão as interconexões, mas como elas verdadeiramente ocorrem. Pelo que percebemos na análise do jogo, ele não nasce como uma rede social, mas é o ponto de partida para que ela se configure, quase em uma 'obrigatoriedade', (dis) função da jogabilidade. Tomando-se as definições de Recuero (2005), os jogadores do WoW estabelecem relações mediadas por computador, motivadas pelo interesse no jogo e mantêm essas relações a ponto de constituir um corpo organizado. Mas o que eles fazem desses relacionamentos? 


\section{¿ compós}

www.e-compos.org.br

| E-ISSN 1808-2599 |
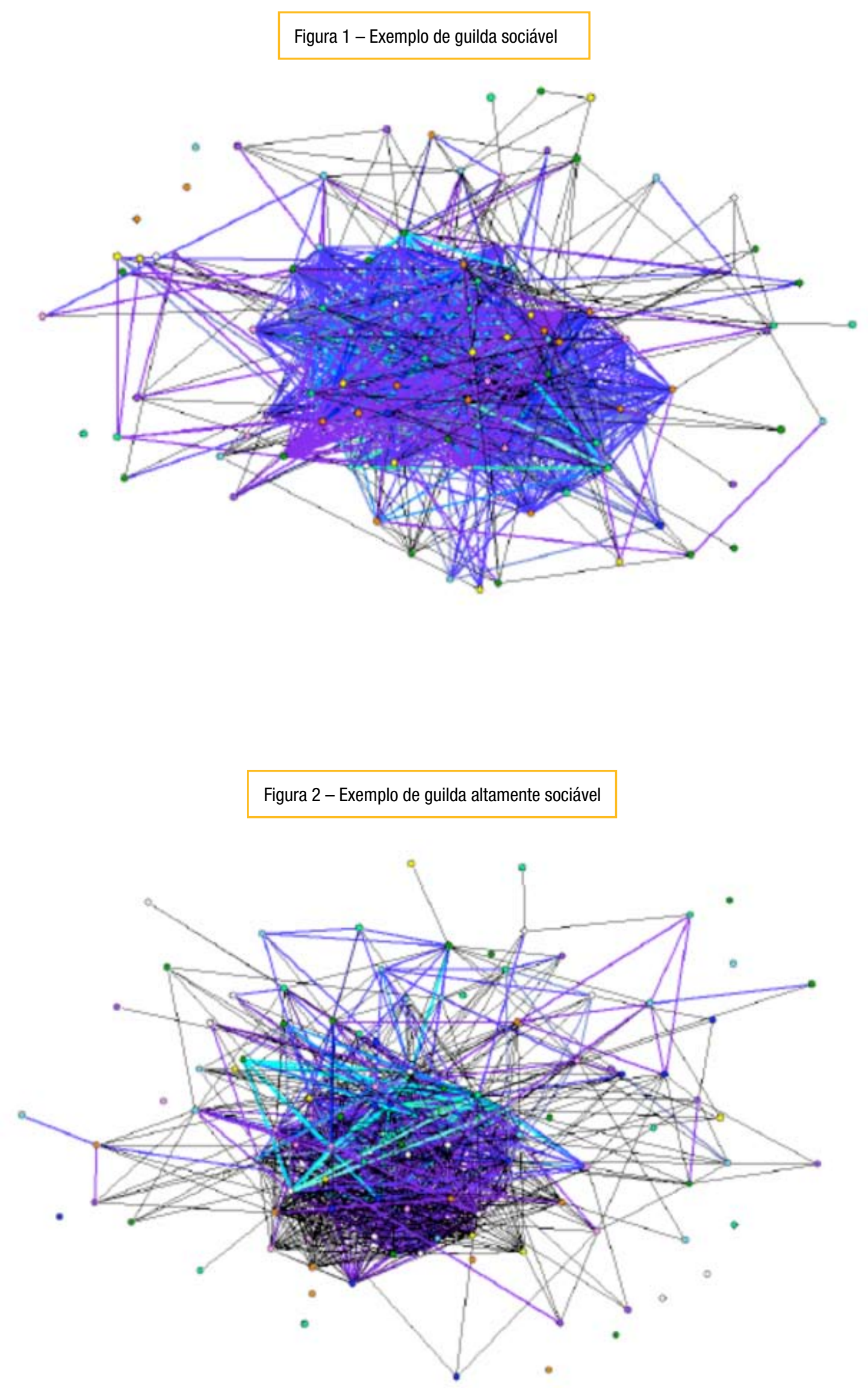


\section{A interação social em (por) World of Warcraft}

No jogo é possível se comunicar com os outros jogadores através de chats abertos nas sessões de batalha e/ou nas interações nas guildas, ou em sistema privado diretamente com algum player em especial. Em todos os casos, a comunicação se dá de maneira síncrona, ou seja, a troca de mensagens é automática, sofrendo apenas os efeitos do 'lag' - uma espécie de atraso no intercâmbio das missivas eletrônicas.

A interface do chat permite não só a troca de dados entre os players, mas também a apresentação de informações do próprio jogo. A interface é personalizável e é possível abrir e modular várias janelas de interação, de acordo com a necessidade de cada jogador. Existe uma variedade de comandos e opções que os jogadores aprendem à medida que vão utilizando a ferramenta. Um elemento que chama a atenção são as várias formas de apropriação do chat, envolvendo não apenas a combinação de linguagens textuais e icônicas, mas opções customizáveis como mudança do tamanho da fonte, cor no plano de fundo de cada janela e formas de representação dos avatares.

Outro aspecto é o da 'memória', apenas disponível para o bate-papo formal dos grupos, e não para as conversas espontâneas, diretas, entre jogadores. No caso das interações de grupo, ao encerrar uma conversa, 0 arquivo fica salvo e aparece recuperado na próxima vez que o jogador abrir o chat, ficando disponível até que o player indique que começará uma nova discussão, para que haja 0 descarte da mensagem.

Quanto à moderação, os diálogos são frequentemente monitorados pela equipe Blizzard Entertainment, mantenedora do jogo, atuando de forma flexível em relação à linguagem. Cada chat tem um moderador (que é 0 administrador do grupo, ou da guilda, ou 0 próprio jogador que abriu o chat direto com outro player), tendo à sua disposição uma série de comandos que permitem o controle dos canais. Há opções de banir o jogador de uma 'sala' ou apenas tirá-lo momentaneamente.

Em 2007, a Blizzard Entertainment apresentou uma nova atualização para o jogo, implementando um bate-papo por intermédio de voz. Antes esse recurso já era utilizado, mas através de adaptações de softwares feitos pelos próprios jogadores, o que indicava a demanda por esse tipo de aplicativo. 0 recurso permite ao jogador falar com seus colegas abertamente no campo de batalha, ou em conversas diretas e privadas. Os canais de comunicação são criados pelos próprios jogadores, o que lhes confere 0 direito à moderação - a convidar, aceitar a entrada e retirar quem o criador do sistema quiser, a qualquer tempo.

Uma série de comunidades e mecanismos de comunicação extra-jogo são criados para fomentar e ampliar a discussão entre os jogadores. Um deles, o mais recente, é o site 
WoWTwitter ${ }^{4}$, que embora siga o mesmo modelo do tradicional Twitter se diferencia deste porque quem participa são os personagens do jogo, os avatares, e o que se comenta nas postagens é justamente sobre as performances no jog $0^{5}$.

0 serviço está disponível em inglês, mas vários brasileiros fazem parte do site que ainda está em uma versão beta. No Brasil existem vários outros sites, fóruns e blogs que promovem a interação extra-jogo. Em relação aos fóruns, a maioria está vinculada a sites mais amplos, prestadores deste tipo de serviço, voltados para os games, como 0 Hangar $^{6}$ - com uma certa tendência/preferência para os MMORPGs, conforme pode ser visto no banner principal do site, e o MMOCentral ${ }^{7}$. Os assuntos são os mais diversos, mas os temas sempre estão relacionados ao jogo. A linguagem é a da metacomunicação, explorando sempre 0 "internetês".

0 mesmo acontece no Orkut, que apresenta uma infinidade de comunidades no Brasil. Contudo, o Orkut tem as suas particularidades e, em alguns casos, são montados fóruns não relacionados aos temas do jogo, onde a receptividade e participação variam de uma comunidade para outra. As mulheres também marcam presença no site e existe até uma comunidade exclusiva delas, "Meninas que jogam WoW", com cerca de 2.400 membros. É interessante observar esse movimento, uma vez que os jogos eletrônicos tradicionalmente são voltados (ou tem maior adesão) para jovens do sexo masculino. № entanto, além de grande participação, as 'meninas' têm até um site exclusivo no Brasil, o WoW Girl .

No Orkut, há ainda a movimentação para que os jogadores se conheçam pessoalmente. 0 apelo nos fóruns que tratam do tema é considerável e desperta 0 interesse em solidificar, ou aumentar, vínculos nascidos no jogo, ampliados em outras ferramentas de interação, no contato físico. No mundo da internet existe uma infinidade de portais e sites sobre 0 WoW onde a temática é reproduzida. Um caso especial é o do Youtube. Uma prática recorrente é a postagem no site de vídeos que mostram as performances dos jogadores nas batalhas. Os usuários comentam imagens, se manifestam com críticas, elogios, além de aproveitar o espaço para fazer perguntas e apresentar sugestões variadas.

Em cada um desses canais, o uso da metacomunicação é recorrente, sendo que o tom

Disponível em: <http://www.wowtwitter.com>. Acesso em: 27 set. 2009.

Conforme o perfil de "Tasken". Disponível em: <http://www.wowtwitter.com/Tweets/Updates/1796>. Acesso em: 27 set. 2009.

Área exclusiva do WoW. Disponivel em: <http://www.hangarnet.com.br/forum/index.php?s=ac11a7c693e2715066b0201671f8c e93\&showforum=28>.

Área exclusiva do WoW. Disponível em: <http://forum.mmocentral.com.br/forumdisplay.php?f=11>. Acesso em: 27 set. 2009.

Na verdade, por descrição, trata-se de um blog. Disponível em: <http://www.wowgirl.com.br/>. Acesso em: 19 set. 2009. 
das mensagens varia de acordo com o momento, o contexto e os indivíduos envolvidos. Há a predominância da cooperação (seja no chat do jogo para alcançar algum objetivo, seja nos fóruns virtuais para tirar dúvidas) e da descontração (sendo o Orkut mais propício para essa condição) na maioria dos processos comunicativos. Em alguns casos, vê-se 0 estabelecimento de trocas enfáticas de informação, por vezes acompanhada de um 'vídeo-tutorial', em que um jogador mais experiente grava sua performance em uma batalha e posta no Youtube. As sessões de comentário podem se tornar verdadeiras áreas de aprendizagem.

Assim, de um modo geral, vê-se o registro da comunicação prioritariamente ligada ao jogo. Há que se enfatizar, aqui, que, por mais que tenhamos realizado uma observação empírica cuidadosa, ela apresenta limitações por não nos permitir esclarecer de maneira satisfatória em que momento termina a interação no jogo e começa a necessidade/desejo de compartilhamento social extra-jogo. Dessa forma, para que pudéssemos avançar em nossa discussão, afastando simples especulações, procuramos saber o que os jogadores pensam e sentem em relação ao jogo.

Um roteiro com 10 perguntas abertas foi elaborado e enviado aos players brasileiros do WoW. 0 método utilizado para a operacionalização do conceito de interação social no WoW e a formulação do questionário baseou-se no modelo recentemente desenvolvido pela linguista Susan Herring (2004), denominado ComputerMediated Discourse Analysis (CMDA), ou Análise do Discurso Mediado por Computador. A CMDA se diferencia de outras formas de análise do discurso porque o seu aparato descritivo e interpretativo leva em consideração as capacidades tecnológicas dos sistemas de CMC.

Herring $(2004 ; 2007)$ especifica dois tipos de aparatos interpretativos como parte da metodologia CMDA. 0 primeiro é 0 esquema de classificação para variáveis contextuais que potencialmente explicam variações na CMC. Essas variáveis, que podem ser adaptadas e complementadas, são de dois tipos abrangentes: tecnológico e situacional. 0 segundo aparato interpretativo é a operacionalização dos conceitos de interesse em termos de características específicas do discurso. A Tabela 1 resume os resultados das variáveis tecnológicas e situacionais que funcionam no WOW.

0 questionário envolveu cinco blocos distintos de perguntas para coletar informações sobre 0 jogo e seus participantes: a) informações sobre o funcionamento e a dinâmica do jogo; b) sobre os costumes do jogador; c) as relações entre os jogadores; d) dados sobre as ferramentas utilizadas para a interação entre os participantes; e, e) sobre a formação de amizades e constituição de ações/eventos no mundo real a partir do virtual.

Uma carta-convite para a participação na pesquisa, garantindo a confidencialidade da 
Tabela 1 - Variáveis tecnológicas e variáveis situacionais

\begin{tabular}{|c|c|}
\hline Variáveis tecnológicas & Variáveis situacionais \\
\hline $\begin{array}{l}\text { Mensagem: } \\
\text { sincronia nas mensagens }\end{array}$ & $\begin{array}{l}\text { Estrutura da participação variada: } \\
\text { - grupos com formação mínima (05 integrantes); } \\
\text { - guildas com mais de } 100 \text { pessoas; } \\
\text { - grupos moderados. }\end{array}$ \\
\hline $\begin{array}{l}\text { Transmissão: } \\
\text { mensagem por mensagem }\end{array}$ & $\begin{array}{l}\text { Característica dos participantes: } \\
\text { - jogadores de várias partes do mundo; } \\
\text { - idade variada; } \\
\text { - superioridade masculina, mas alta } \\
\text { representatividade feminina; } \\
\text { - descontração nas relações e disciplina no jogo; } \\
\text { - motivação pelo jogo, manutenção pelo jogo } \\
\text { e relacionamentos. }\end{array}$ \\
\hline $\begin{array}{l}\text { Buffer de memória: } \\
\text { limitado }\end{array}$ & $\begin{array}{l}\text { Propósito da comunicação: } \\
\left.1^{\circ}\right) \text { necessidade primária do jogo; } \\
2^{\circ} \text { ) desenvolvimento no jogo; } \\
3^{\circ} \text { ) entretenimento; } \\
4^{\circ} \text { ) estabelecimento de laços afetivos. }\end{array}$ \\
\hline $\begin{array}{l}\text { Persistência da cópia: } \\
\text { cópia deletada }\end{array}$ & $\begin{array}{l}\text { Tópico: } \\
\left.1^{\circ}\right) \text { necessidades do jogo; } \\
2^{\circ} \text { ) estratégias. }\end{array}$ \\
\hline $\begin{array}{l}\text { Canais de comunicação: } \\
\text { textual e áudio }\end{array}$ & $\begin{array}{l}\text { Tom das mensagens: } \\
\text { cooperativo, descontraído, objetivo, amigável. }\end{array}$ \\
\hline $\begin{array}{l}\text { Autoria das mensagens: } \\
\text { avatares }\end{array}$ & $\begin{array}{l}\text { Normas: } \\
\text { - grupos moderados pelos jogadores. as regras variam } \\
\text { de grupo para grupo; } \\
\text { - é proibido falar palavrões, fazer discriminações } \\
\text { e manifestar preconceitos; } \\
\text { - as sanções envolvem suspensão e banimento } \\
\text { de jogadores, de acordo com o grau da infração. }\end{array}$ \\
\hline $\begin{array}{l}\text { Filtros: } \\
\text { moderadores (os próprios jogadores) }\end{array}$ & $\begin{array}{l}\text { Código linguístico: } \\
\text { metacomunicação }\end{array}$ \\
\hline
\end{tabular}

identidade real dos jogadores, foi divulgada na

primeira semana de maio de 2009 em um fórum

específico e em duas comunidades relevantes do

Orkut, além de ter sido enviada por e-mail para

jogadores indicados por um player brasileiro

cadastrado e bastante ativo no jogo. A carta-

convite explicava que as entrevistas seriam feitas exclusivamente por e-mail aberto pelos

responsáveis da pesquisa, vinculado ao domínio da

Universidade Federal de Minas Gerais (UFMG).

Ao todo, 12 questionários completos foram

respondidos, sendo 40\% da Região Metropolitana

de Belo Horizonte e $60 \%$ de outras regiões

brasileiras. Para os fins exploratórios desta 
pesquisa, devido à ausência de dados estatísticos sobre os jogadores brasileiros e o caráter qualitativo da pesquisa, consideramos o número de questionários respondidos como representativo para uma análise das interações no WoW.

A partir dos dados da pesquisa, analisou-se que a maioria dos jogadores pesquisados considera 0 WoW um jogo de qualidade, com diferenciais e vantagens em relação a outros jogos do mesmo segmento. De acordo com os players, neste jogo existe um sistema de evolução plausível, além da vantagem de se ter um PvP (player vs. player) diferenciado e de boa qualidade, caracterizado como um dos principais meios de interação e de combate direto. Segundo um entrevistado, os "jogos online são mais divertidos e proporcionam relacionamentos com pessoas do mundo inteiro, 0 que deixa o jogo mais atrativo".

Conforme afirmamos anteriormente, dois tipos de comunicação entre players são utilizados no jogo, o chat textual e o de voz. Este último foi citado como o mais empregado entre jogadores de grandes grupos, principalmente em disputas, quando não há como parar de lutar para digitar uma mensagem. Assim, essas ferramentas de comunicação se tornam mais fáceis e de rápida percepção. Porém, os jogadores pesquisados afirmam ainda que outros meios e ferramentas, que não passam pelo funcionamento do jogo em si, são utilizados para a comunicação sobre 0 jogo. Os jogadores utilizam o Skype, MSN, Orkut e fóruns de discussão.
Na análise das respostas dos entrevistados, constatou-se que, realmente, nas guildas os jogadores se reúnem pelo mesmo ideal, indo além dos objetivos em comum que 0 jogo propõe. Nas guildas, as pessoas costumam se juntar por afinidade, 0 que facilita 0 trabalho nas raids e instâncias. Neste caso, confirmamos através dos questionários que, enquanto nas raids a formação se dá pelo intuito de conquistar determinados objetivos, as guildas geram proximidade e quebram as barreiras do formalismo do jogo, abrindo oportunidade para 0 entrosamento, baseado no reconhecimento das afinidades.

Nos grupos formados no WoW, a liderança dificilmente é exercida pelo carisma, mas pelo conhecimento que o jogador tem e a habilidade que demonstra, evidenciando que o objetivo do jogo, inicialmente, é maior do que a própria interação social. De acordo com um participante da pesquisa, "é nos líderes que se concentra 0 controle dos grupos, são eles que podem fazer os convites, excluir membros, gerir a organização do grupo". 0 conjunto desses sistemas de grupo compõe a rede social online do WarCraft, que gera uma extensão fora do jogo e também 0 inverso, pois pessoas que já se conhecem do lado de fora podem formar grupos dentro do jogo, como é 0 caso da possibilidade que o jogo oferece através do "recruit-a-friend", disponível no site, amplamente conhecido e utilizado por nossos respondentes. 
Os achados da pesquisa mostram, ainda, que os participantes do WoW jogam em média seis horas por dia. Nos finais de semana, chegam a ficar conectados por cerca de 10 horas. Durante esse período, o jogador interage com várias pessoas e o objetivo do jogo é a expansão, ou seja, o ganho de nível - projeção das capacidades do avatar. A maioria dos jogadores pesquisados afirma que 0 jogo proporciona essa interação e, a partir daí, foram geradas várias amizades dentro do game, com o objetivo de se ajudarem no decorrer do jogo (o que é o foco central dos grupos formados) e até mesmo na vida real.

Um entrevistado afirmou que já deve ter feito "no mínimo uns 30 amigos através do jogo, recebendo convites para [ir a] casamentos, festas e aniversários". Outro jogador demonstra as possibilidades de interação e de estabelecimento de laços, observando que "é um mundo incrível a ser descoberto com pessoas de todas as formas e de todos os lugares", e conclui que "em WoW o processo se assemelha a uma vida real, onde inevitavelmente acontece uma interação, seja ela de várias formas e dependendo da circunstâncias que se encontra".

Segundo pesquisa do web site MMORPG.COM (2007), a maior motivação para jogar, além do jogo em si, é "socializar com os amigos", e isso se confirmou em algumas respostas transcritas a seguir: "eu sou mais focado nas missões, mas possuo amigos em game, afinal é a graça de um MMORPG"; "eu diria que no jogo as pessoas interagem melhor devido à dependência para seguir os objetivos"; "como em qualquer atividade on-line, se formam muitas amizades no jogo"; "eu acho que para manter um bom jogo você tem que ter amigos que jogam, para poder interagir, conversar sobre o jogo. Eu faço missões, mas também converso muito com meus amigos da 'guilda' e da rua".

Além disso, por vezes é perceptível que as barreiras entre 0 'real' e 0 'ficcional' variam; ora estão bem marcadas, ora são tênues, e em outros momentos nem parecem existir: "o jogo é uma espécie de distração da vida real. Nele você tem um ambiente que encontra amigos, inimigos. [...] [Há] uma necessidade de falar com os amigos, interagir, se divertir, que é o mais importante"; "é como na vida real, as pessoas se conhecem e formam os círculos de amizade".

As respostas são das mais variadas, mas sempre dão a dimensão do quanto o estabelecimento de vínculos sociais é evidente no jogo, o que demonstra o seu caráter interacionista. Um respondente disse: "consigo enxergar o vício de meus amigos, e sempre faço a eles esse tipo de pergunta [que motivos mantêm, verdadeiramente, você jogando, e o que leva tantas pessoas ao 'vício'?], alguns respondem sinceramente, outros se irritam comigo". Outro entrevistado disse: "não me interajo muito com todos eles, há os principais amigos que sempre que entro no jogo já vou recebendo whispers deles"; e um outro afirmou: "alguns até considero 
amigos mesmo, pois sempre me ajudam em momentos de necessidades e os conheço há um bom tempo".

\section{Considerações, inferências e questionamentos}

A rede social no WoW nasce e se mantém, majoritariamente, por necessidade. Ela se estabelece em função das prerrogativas do jogo, no que concerne ao agrupamento para a realização de atividades diversas - sobretudo àquelas que fomentam/geram pontuação para 0 avatar, e outras como as relações de compra e ligações dadas em um mundo virtual, que reproduz algumas dinâmicas do mundo concreto. Contudo, essas interconexões apenas demonstram a existência da rede.

As especificidades se dão em função da interação social, que também nasce por 'interesse' - em aprender a jogar, a conhecer as artimanhas do jogo, em ser aceito em grupos (guildas) fortes, visando a sua proteção no game. A interação se desenvolve pelo reconhecimento de afinidades, no estabelecimento de contatos que extrapolam o conteúdo do jogo. Outra condição evidente é a auto-confiança que o jogador desenvolve à medida que ganha experiência no jogo. 0 'crescimento' do player no jogo influencia nos contatos (e em sua tipologia), e depende do perfil de cada um e de seus objetivos.

Essa interação concebida por 'interesse'/ necessidade, e que se desenvolve por afinidade, se mantém em função do interacionismo

simbólico. Essa ideia é de difícil explicitação, pois nem os próprios players têm noção sobre isso, apesar de darem embasamento para tanto em suas respostas, cabendo a nós inferir acerca de cada expressão. É perceptível que as relações que se dão a partir do, ou no jogo, estão carregadas de significados e de muitos outros elementos.

\section{Blumer enfatizou que o interacionismo simbólico retrata o mundo social como gerado pelas intera- ções sociais, interação que em si produz, e é mo- delada, pela interpretação dos participantes do mundo. Esse processo de interação é formativo e criativo, não é composto de respostas automá- ticas aos estímulos. A ordem social, portanto, é instável e contingente, perpetuadamente recons- truída pelos atores. É o produto temporariamente institucionalizado de interações indeterminadas. (JOHNSON, 2010, p. 95-96).}

A título de exemplo, retiramos uma passagem interessante do texto de Rodrigues e Mustaro. Apesar de terem o foco voltado para as conexões matemáticas, as pesquisadoras ressaltam que 0 jogo, digital ou não, constitui parte da cultura humana por seu valor expressivo:

Este relaciona-se a uma das principais características do jogo: 0 'faz de conta'. A fantasia pertinente aos jogos foi revolucionada pela tecnologia, que instituiu um ambiente gráfico interativo denominado de universo virtual. Este é complementado pelo fluxo da narrativa, que também constitui elemento de destaque em relação à interação e à imersão do jogador. (RODRIGUES; MUSTAR0, 2008, p. 31).

Esse mundo do fantástico, do subliminar, da imaginação, ao mesmo tempo é concreto. 
Possibilita tanto expressar-se sem as barreiras socialmente aceitáveis no mundo 'real', quanto demonstrar o que de fato aquele que joga pensa - uma vez que nem sempre tem este espaço no mundo 'real'. Ao mesmo tempo em que 0 'virtualficcional' poderia se configurar como um refúgio das 'pressões' da vida material, oferece certo conforto e a sensação de (vi)ver (n)um mundo em que a noção de verdade se estabelece no que a história dita. Ao passo que é previsível, é proporcionalmente menos artificioso que 0 'real'. Estaríamos, no entanto, interessados em questionar como são exportados esses elementos simbólicos do ficcional, a significação desse 'mundo paralelo', para as relações entre as pessoas (in-game).

É preciso levar em consideração que esse mundo de 'fantasia', contudo, tem os pés na realidade. A pergunta que aparece, e ditaria, com sua resposta, o rumo de uma conclusão, seria: o relacionamento se dá entre avatares ou entre humanos representados por essas figuras virtuais? Evidentemente (nem tanto) que entre pessoas; mas abrir-se-iam outras questões; por exemplo, se essa relação seria a mesma, se haveria a mesma disponibilidade em comunicarse, em interagir, em 'abrir-se', em se performar de uma determinada maneira, que não através desta ferramenta ( $0 \mathrm{WoW}$ ), que ao mesmo tempo esconde 0 'rosto' por detrás do personagem. Aliás, 0 WoW mascara a identidade 'real' do jogador ou lhe daria espaço para apresentar sua verdadeira face, ou ainda, o que gostaria de ser? Talvez, nesse âmbito, o trabalho tenha trazido mais interrogações do que afirmações, mas não deixa de oferecer pistas, pois suscita a possibilidade de uma gama de discussões no universo das redes e interações sociais em jogos on-line.

$\mathrm{Na}$ análise e interpretação dos dados, sugerimos que as comunidades do WoW apresentam uma diversidade cultural determinada pelos tipos de laços sociais estabelecidos no ambiente virtual do jogo. Os laços se mostraram em vários níveis, de fortes a fracos, sendo formados de maneiras distintas. Uma categorização de seis laços pode ser indicada: a) laços de nível de objetividade do jogo; b) laços relacionados às inclinações pessoais e dos grupos, sejam por características e/ou preferências; c) laços de localidade ingame (localização geográfica do jogador no universo virtual do jogo) e out-game (localização geográfica do jogador no mundo real); d) laços estabelecidos de fora para dentro do jogo, e de dentro para fora do jogo; e) laços de amizades que migraram de outros jogos e/ou outras redes sociais; e finalmente, c) laços determinados por um amigo comum ("amigo de um amigo").

Ao retomar as perguntas que animaram este estudo, seria possível dizer que o relacionamento entre as pessoas seria o mesmo no Orkut antes do jogo? Com base no entendimento do funcionamento desta rede social em particular, 
percebemos o cruzamento de indivíduos em comunidades diversas, mas o relacionamento entre as pessoas dificilmente acontece ao ponto de se 'adicionarem' mutuamente por suas afinidades (que são também cruzadas). Contudo, pessoas com perfis e vidas completamente diferentes se identificam no WoW e estendem essa relação para outras mídias.

Por fim, ratificamos a necessidade de aprofundamento no estudo das redes sociais em jogos online e, mais do que isso, das interações sociais que se estabelecem nos, e a partir dos, games. É preciso compreender os elementos que regem as relações entre as pessoas nesses mundos, a fim de entender um fenômeno que, mesmo com a grande dimensão apresentada atualmente, pode ser apenas o início de um movimento muito maior. Não se conjectura o 'fim' do 'real', mas uma convivência cada vez mais próxima entre esses dois 'espaços'. Compreende-se, que "[...] esses novos ambientes sociais online precisam ser observados, estudados e compreendidos como espaços de significações que levam os agentes a agir como agem em seus próprios contextos em processos localizados de interação social" (JOHNSON, 2008, p. 11).

\section{Referências}

BLAU, Peter. Presidential address: parameters of social structure. American Sociological Review, Washington D.C., v. 21, p. 615-625, 1974.
BURT, Ronald. Models of network structure. Annual Review of Sociology, Palo Alto, v. 6, p. 79-141, 1980. COLEMAN, James. Foundations of social theory. Cambridge, MA: The Belknap Press of Harvard University, 1990.

COLINA, Carlos et al. Relaciones, redes y discurso: revisión y propuestas en torno al análisis reticular de datos textuales. Revista hispana para el análisis de redes sociales, Barcelona, v. 1, jan. 2002. Disponível em: http://revista-redes.rediris.es/ Acesso em: 20 fev. 2009

EC0, Umberto. Seis passeios pelos bosques da ficção. São Paulo: Companhia das Letras, 1994.

FRANÇA, Vera R. Veiga. Do telégrafo à rede: 0 trabalho dos modelos e a apreensão da comunicação. In: PRADO, José L. A (Org.). Crítica das práticas midiáticas: da sociedade de massa às ciberculturas. São Paulo: Hacker, 2002. p. 57-76.

HERRING, Susan. A faceted classification scheme for computer-mediated discourse. In: Language@ Internet. 2007. Disponível em: <http://www. languageatinternet.de/articles/2007/761>. Acesso em: 7 abr. 2008.

HERRING, Susan. Online communication: through the lens of discourse. Internet research Annual, New York, v. 1, p. 65-76, 2004.

JOHNSON, Telma. Nos bastidores da Wikipédia Lusófona: percalços e conquistas de um projeto de escrita coletiva on-line. Rio de Janeiro: E-papers, 2010.

JOHNSON, Telma. 0 naturalismo metodológico de $\mathrm{H}$. Blumer: contribuições para as práticas de pesquisa em cibercultura. In: ENCONTRO DA ASSOCIAÇÃO BRASILEIRA DE PROGRAMAS DE PÓS-GRADUAÇÃO EM COMUNICAÇÃo, 17., 2008, São Paulo. Anais... São Paulo: Compós, 2008. Disponível em: <http://www. compos.org.br/data/biblioteca_293.pdf>. Acesso em: 25 mai 2010. 
MMORPG.COM., Features - Polls - Aside from

questing, what do you spend most of your time

doing in-game? Disponível em: <http://mmorpg.com/

features.cfm/view/polls >. Acesso em: 7 Jul. 2007.

PEARLIN, Leonard; ANESHENSEL, Carol. Coping and social supports: their functions and applications. In: MECHANIC, David; AIKEN, Linda (eds.). Applications of social science to clinical medicine and healthy policy. New Brunswick: Rutgers University Press, 1986. p. 417-437.

RECUER0, Raquel. Comunidades virtuais em redes sociais na internet: uma proposta de estudo .

E-compós, Brasília, v.4, dez 2005.

RODRIGUES, Lia C.; MUSTARO, Pollyana N.

Desenvolvimento de coleta de dados automatizada para Análise de Redes Sociais de Comunidades de Jogos On-line. Apresentado no Workshop on Information Visualization and Analysis in Social Networks - WIVA 2008 - Programa de Pós-Graduação em Engenharia Elétrica - Universidade Presbiteriana Mackenzie (UPM), São Paulo. Disponível em: <http:// www.lbd.dcc.ufmg.br:8080/colecoes/wiva/2008/004. pdf>. Acesso em: 20 set. 2009. 


\section{Social networks in online games: the dynamics of social interaction within World of Warcraft}

\section{Abstract}

This article approaches the dynamics of social interaction between players of the online game World of Warcraft (WoW). The theoretical-methodological trajectory follows a relationship orientation focused on three dimensions - structure, content and function - for the apprehension of the communicative processes and practices in the WoW environment. The work, which is qualitative in nature, values the reading of the actual players concerning the factors that explain the establishment and maintenance of a social network that surpasses the limits of the game and is indeed amplified through other models of virtual socialization, which is even fortified by physical contact.

\section{Keywords}

Interaction. Games. Computer

Mediated Communication (CMC).
Las redes sociales en los juegos online: la dinámica de la interacción social en World of Warcraft

\section{Resumen}

Este artículo aborda la dinámica de la interacción social entre los actores del juego en línea World of Warcraft (WoW). La trayectoria teóricometodológica sigue una orientación relacional centrada en tres dimensiones - estructura, contenido y función - para la aprehensión de los procesos comunicativos y las prácticas en el entorno de WoW. El trabajo, que es de naturaleza cualitativa, valoriza la lectura de los actores reales sobre los factores que explican el establecimiento y mantenimiento de una red social que supera los límites del juego, se amplía a través de otros modelos de socialización virtual y se basa en el contacto físico.

\section{Palabras clave}

Interacción. Juegos. Comunicación

Mediada por Computador (CMC). 


\section{Expediente}

A revista E-Compós é a publicação científica em formato eletrônico da Associação Nacional dos Programas de Pós-Graduação em Comunicação (Compós). Lançada em 2004, tem como principal finalidade difundir a produção acadêmica de pesquisadores da área de Comunicação, inseridos em instituições do Brasil e do exterior.

\section{E-COMPÓS I www.e-compos.org.br I E-ISSN 1808-2599}

Revista da Associação Nacional dos Programas de Pós-Graduação em Comunicação. Brasília, v.13, n.1, jan./abr. 2010.

A identificação das edições, a partir de 2008 passa a ser volume anual com três números.

\section{CONSELHO EDITORIAL}

Afonso Albuquerque

Universidade Federal Fluminense, Brasil

Alberto Carlos Augusto Klein

Universidade Estadual de Londrina, Brasil

Alex Fernando Teixeira Primo

Universidade Federal do Rio Grande do Sul, Brasil

Alfredo Vizeu

Universidade Federal de Pernambuco, Brasi

Ana Carolina Damboriarena Escosteguy

Pontifícia Universidade Católica do Rio Grande do Sul, Brasil

Ana Silvia Lopes Davi Médola

Universidade Estadual Paulista, Brasil

André Luiz Martins Lemos

Universidade Federal da Bahia, Brasil

Ângela Freire Prysthon

Universidade Federal de Pernambuco, Brasil

Antônio Fausto Neto

Universidade do Vale do Rio dos Sinos, Brasil

Antonio Carlos Hohlfeldt

Pontifícia Universidade Católica do Rio Grande do Sul, Brasil

Arlindo Ribeiro Machado

Universidade de São Paulo, Brasil

César Geraldo Guimarães

Universidade Federal de Minas Gerais, Brasil

Cristiane Freitas Gutfreind

Pontifícia Universidade Católica do Rio Grande do Sul, Brasil

Denilson Lopes

Universidade Federal do Rio de Janeiro, Brasil

Eduardo Peñuela Cañizal

Universidade Paulista, Brasil

Erick Felinto de Oliveira

Universidade do Estado do Rio de Janeiro, Brasil

Francisco Menezes Martins

Universidade Tuiuti do Paraná, Brasil

Gelson Santana

Universidade Anhembi/Morumbi, Brasil

Goiamérico Felício

Universidade Federal de Goiás, Brasil

Hector Ospina

Universidad de Manizales, Colômbia

Herom Vargas

Universidade Municipal de São Caetano do Sul, Brasil

leda Tucherman

Universidade Federal do Rio de Janeiro, Brasil

Itania Maria Mota Gomes

Universidade Federal da Bahia, Brasil

Janice Caiafa

Universidade Federal do Rio de Janeiro, Brasil

Jeder Silveira Janotti Junior

Universidade Federal da Bahia, Brasil
João Freire Filho

Universidade Federal do Rio de Janeiro, Brasil

John DH Downing

University of Texas at Austin, Estados Unidos

José Luiz Aidar Prado

Pontifícia Universidade Católica de São Paulo, Brasil

José Luiz Warren Jardim Gomes Braga

Universidade do Vale do Rio dos Sinos, Brasil

Juremir Machado da Silva

Pontifícia Universidade Católica do Rio Grande do Sul, Brasil

Lorraine Leu

University of Bristol, Grã-Bretanha

Luiz Claudio Martino

Universidade de Brasília, Brasil

Maria Immacolata Vassallo de Lopes

Universidade de São Paulo, Brasil

Maria Lucia Santaella

Pontifícia Universidade Católica de São Paulo, Brasil

Mauro Pereira Porto

Tulane University, Estados Unidos

Muniz Sodre de Araujo Cabra

Universidade Federal do Rio de Janeiro, Brasil

Nilda Aparecida Jacks

Universidade Federal do Rio Grande do Sul, Brasil

Paulo Roberto Gibaldi Vaz

Universidade Federal do Rio de Janeiro, Brasil

Renato Cordeiro Gomes

Pontifícia Universidade Católica do Rio de Janeiro, Brasil

Ronaldo George Helal

Universidade do Estado do Rio de Janeiro, Brasil

Rosana de Lima Soares

Universidade de São Paulo, Brasil

Rossana Reguillo

Instituto Tecnológico y de Estudios Superiores do Occidente, México

Rousiley Celi Moreira Maia

Universidade Federal de Minas Gerais, Brasil

Samuel Paiva

Universidade Federal de São Carlos, Brasil

Sebastião Albano

Universidade Federal do Rio Grande do Norte, Brasil

Sebastião Carlos de Morais Squirra

Universidade Metodista de São Paulo, Brasil

Simone Maria Andrade Pereira de Sá

Universidade Federal Fluminense, Brasil

Suzete Venturelli

Universidade de Brasília, Brasil

Valério Cruz Brittos

Universidade do Vale do Rio dos Sinos, Brasil

Veneza Mayora Ronsini

Universidade Federal de Santa Maria, Brasil

Vera Regina Veiga França

Universidade Federal de Minas Gerais, Brasil

\section{COMISSÃO EDITORIAL}

Felipe da Costa Trotta I Universidade Federal de Pernambuco, Brasil Rose Melo Rocha I Escola Superior de Propaganda e Marketing, Brasil CONSULTORES AD HOC

João Maia I Universidade do Estado do Rio de Janeiro, Brasil Sandra Gonçalves I Universidade Federal do Rio Grande do Sul, Brasil Mayra Rodrigues Gomes I Universidade de São Paulo, Brasil Gisela Castro I Escola Superior de Propaganda e Marketing, Brasil João Carrascoza I Escola Superior de Propaganda e Marketing, Brasil Luciana Pellin Mielniczuk I Universidade Federal de Santa Maria, Brasil Irene de Araújo Machado I Universidade de São Paulo, Brasil Hermilio Pereira dos Santos Filho I Pontifícia Universidade Católica, Brasil Benjamim Picado I Universidade Federal Fluminense, Brasil Maria Apaecida Baccega I Escola Superior de Propaganda e Marketing, Brasil Rogério Ferraraz I Universidade Anhembi Morumbi, Brasil

Bruno Souza Leal I Universidade Federal de Minas Gerais, Brasi REVISÃO DE TEXTO E TRADUÇÃo I Everton Cardoso EDITORAÇ̃̃ ELETRÔNICA I Roka Estúdio
COMPóS I www.compos.org.br

Associação Nacional dos Programas de Pós-Graduação em Comunicação

Presidente

Itania Maria Mota Gomes

Universidade Federal da Bahia, Brasil

itania@ufba.br

Vice-presidente

Julio Pinto

Pontifícia Universidade Católica de Minas Gerais, Brasil juliopinto@pucminas.br

Secretária-Geral

Ana Carolina Escosteguy

Pontifícia Universidade Católica do Rio Grande do Sul, Brasil carolad@pucrs.br 